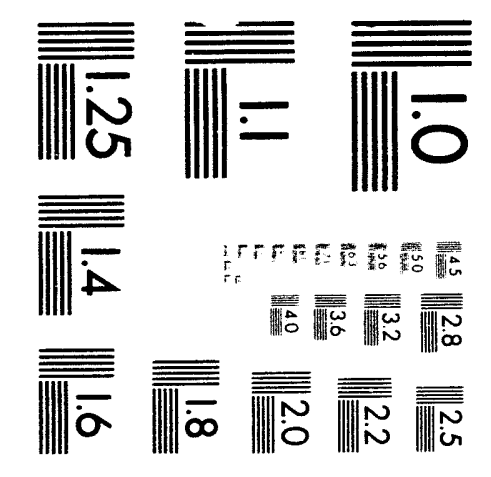



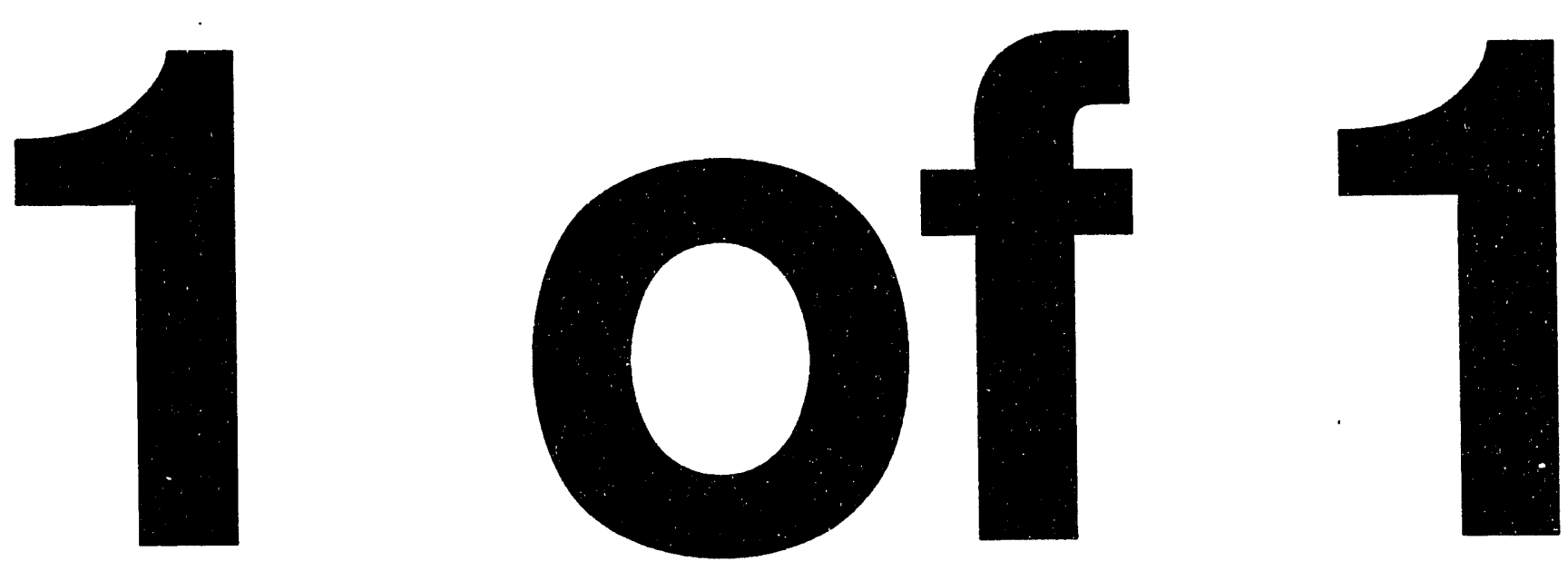


\section{Conf-930960 -. 4}

UCRL- JC -113838

PREPRINT

\section{Accelerator Mass Spectrometry in Biomedical Research}

J.S. Vogel and K.W. Turteltaub

This paper was prepared for submittal to the 6th International Conference on Accelerator Mass Spectrometry

Canberra-Sydney, Australia

September 27 - October 1, 1993

October 20, 1993

I his is a preprint of a paper intended for publication in a journal or proceedings. Since changes may be made before publication, this preprint is made available with the understanding that it will not be cited or reproduced without the permission of the author.

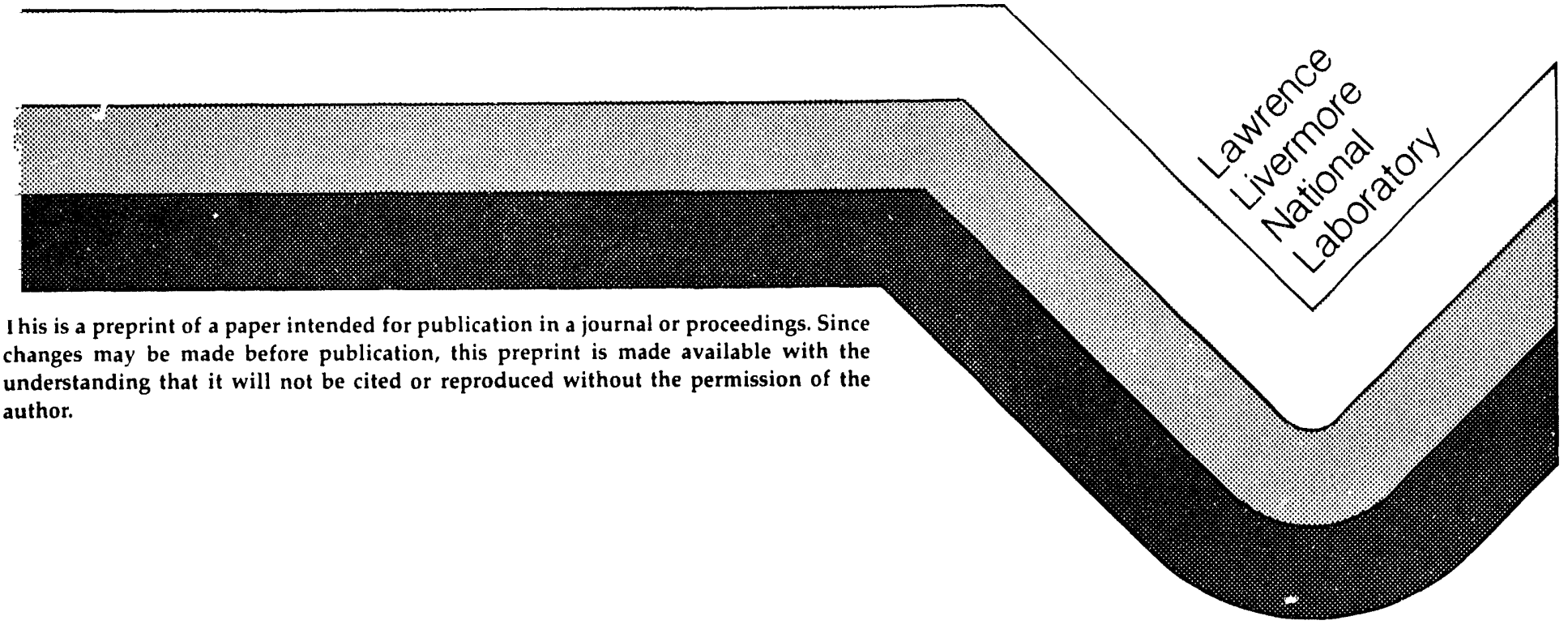




\section{DISCLAIMER}

This document was prepared as an account of work sponsored by an agency of the United States Government. Neither the United States Government nor the University of California nor any of their employees, makes any warranty, express or implied, or assumes any legal liability or responsibility for the accuracy, completeness, or usefulness of any information, apparatus, product, or process disclosed, or represents that its use would not infringe privately owned rights. Reference herein to any specific commercial products, process, or service by trade name, trademark, manufacturer, or otherwise, does not necessarily constitute or imply its endorsement, recommendation, or favoring by the United States Government or the University of California. The views and opinions of authors expressed herein do not necessarily state or reflect those of the United States Government or the University of Califomia, and shall not be used for advertising or product endorsement purposes. 


\title{
Accelerator Mass Spectrometry in Biomedical Research
}

\author{
J.S. Vogel and K.W. Turteltaub ${ }^{1.1}$ \\ Center for AMS, L-397 and \\ 1) Biology and Biotechnology Research Program, L-452 \\ Lawrence Livermore National Laboratory, University of California \\ Livermore, CA 94550 USA
}

\begin{abstract}
Biological effects occur in natural systems at chemical concentrations of parts per billion $\left(1: 10^{9}\right)$ or less. Affected biomolecules may be separable in only milligram or microgram quantities. Quantification at attomole sensitivity is needed to study these interactions. AMS measures isotope concentrations to parts per $10^{13.15}$ on milligram-sized samples and is ideal for quantifying long-lived radioisotopic labels that are commonly used to trace biochemical pathways in natural systems. ${ }^{14} \mathrm{C}$ AMS has now been coupled to a variety of organic separation and definition technologies. Our primary research investigates pharmacokinetics and genotoxicities of toxins and drugs at very low doses. Human subject research using AMS includes nutrition, toxicity and elemental balance studies. ${ }^{3} \mathrm{H},{ }^{11} \mathrm{Ca}$ and ${ }^{26} \mathrm{Al}$ are also traced by AMS for fundamental biochemical kinetic research. Expansion of biomedical AMS awaits further development of biochemical and accelerator technologies designed specifically for these applications.
\end{abstract}

\section{Introduciion}

At the Paris AMS Conference in 1990, we witnessed the first practical steps in making AMS a useful technology in biomedical research. Two papers discussed tracing aluminum metabolism in rodents[1] and a man[2], one paper discussed the detection of ${ }^{41} \mathrm{Ca}$ for bone resorption studies[3], the use of ${ }^{365} \mathrm{Cl}$ measurements in 
determining the neutron doses that affected Hiroshima survivors was described[4], a SIMS ion source for the spatial tracing of ${ }^{14} \mathrm{C}$ in neuroscience was shown[5], and our facility presented two papers about tracing organic compounds in living systems using a ${ }^{14} \mathrm{C}$ label $[6,7]$. We all spoke of the untapped potential for AMS to provide exciting new sensitivity for studying biochemical interactions at relevant levels in vitro and, more importantly, in vivo.

During the past three years these studies have expended. ${ }^{26} \mathrm{Al}$ has continued to be used in studying aluminum metabolism [8-10] and as an adjuvant in immunoresponse studies [D. Elmore, pers. commun.]. ${ }^{41} \mathrm{Ca}$ is periodically measured from the blood of a physician who will personally remain an important source of information about hormonal effects on bone resorption for many years [J. Prior, pers. commun.] University of California researchers are developing ${ }^{41} \mathrm{Ca}$ as a tracer for calcium uptake and deposition in cardiac ischemia[11]. The studies of the Hiroshima neutron flux are being refined using both ${ }^{36} \mathrm{Cl}$ and ${ }^{41} \mathrm{Ca}[12,13]$. Initial experiments using tritium to study pharmacokinetics have been done after development of new sample presentation techniques[14]. ${ }^{14} \mathrm{C}$, however, has seen the greatest continued application, with studies in protein turnover rates in humans[15], normal and abnormal effects in dermal absorption[16], and a number of studies concerning the kinetics and specific binding properties of carcinogens and toxins [1 $i-22]$. Finally, SIMS/AMS for biomedical imaging has been succesfully demonsıated[23]. Despite expansion in biomedical AMS applications, these studies are a very small fraction of the total world effort in AMS.

The biological research community appears slower in adopting AMS as a tool than the geo-chronometry community did decade ago, but the learning curves are similar despite the decade of AMS advancement between them. We could compare ${ }^{14} \mathrm{C}$ dating by AMS in 1983, five years after its introduction, to the use of biomedical " $\mathrm{C}$ AMS at present, five years after our initial efforts in 1988. The primary obstacles in both instances are nearly identical: Accelerator facilities for biomedical AMS, are few and the access seems limited to in-house research. The ultimate solution to reliable and rapid sample presentation is not yet known. We are not certain that we have the best possible ion source for the job. The AMS samples are sufficiently small that the association with the desired property must be proven to skeptics. The methods for identifying and handling the samples without contamination are being 
developed. Finally, there is resistance to base a research program on a technology that is not yet proven in the field. There is obvious need for instrumnental development in biomedical AMS, but this paper shows the continued applicability of AMS to biomedical research with examples that involve newer phases of biochemical definition prior to AMS quantification.

\section{AMS: the attomole detector}

When AMS was first promoted for ${ }^{14} \mathrm{C}$ dating, the relationship between an AMS determination and the familiar "conventional radiocarbon date" was often questioned and sometimes doubted. Through laboratory calibrations and collaborative intercomaprisons[24], AMS was proven to provide the equivalent of a conventional date and is now accepted for ${ }^{14} \mathrm{C}$ chronometry. We similarly find an resistance to ${ }^{14} \mathrm{C}$-AMS as a biomedical tool, since the present technology is more complex than the familiar scintillation counters and the reported quantity is unfamiliar. We must relate the sensitivity of AMS in known terms and protocols to emphasize its value to the biomedical community.

Routine sensitivity of ${ }^{14} \mathrm{C}$ dating is remarkable in terms of chemical tracing and is of the order required in biomedical studies of chemical exposure levels that are relevant to those found in the daily environment. Drugs, toxins, and minor nutrients are effective at picogram to milligram amounts in a normal human. Grossly assuming a uniform distribution in a $70 \mathrm{~kg}$ person, these amounts translate to between 300 zeptomoles $\left(\mathrm{zmol},=10^{-21} \mathrm{~mole}\right)$ to picomoles per $\mathrm{mg}$ of carbon. ${ }^{14} \mathrm{C}$-AMS measurements often provide results in terms of "Modern" or as isotope ratios, where Modern materials contain 97.9 attomoles of ${ }^{14} \mathrm{C}$ per mg of carbon. Thus, a $1 \%$ precise measure of a contemporary ${ }^{14} \mathrm{C}$ level is determined to \pm 1 attomole per mg carbon. and a sensitivity above background of just 1\% Modern also represents 1 attomole of tracer per $\mathrm{mg}$ carbon. Since samples of $0.1 \mathrm{mg}$ are easily handled, the tracing resolution of AMS using ${ }^{14} \mathrm{C}$ is approximately $100 \mathrm{zmol}$. In an ion source that is also used for ${ }^{14} \mathrm{C}$ dating, it is best to keep samples under 1000 Modern if the source is to be "self-cleaning" to $0.2 \%$ Modern or better in an hour or less. Thus the effective upper limit of ${ }^{14} \mathrm{C}$ tracing with AMS is $100 \mathrm{fmol}\left(10^{-15}\right.$ moles) of tracer isotope. The sensitivity for heavier ions such as ${ }^{26} \mathrm{Al}$ and ${ }^{41} \mathrm{Ca}$ cover a similar range from 
zeptomoles to femtomoles. AMS is one of the few technologies that offers maximal sensitivity at attomole levels and has an accurate dynamic range up to $100 \mathrm{fmol}$.

The primary competing technology for attomole detection in biomedicine is laser fluorescence. Many molecules fluoresce at identifiable frequencies, and fluorescent moities can often be attached to other biomolecules for identification, as is done in laser-fluorescent enzyme-linked immunoassays. However, unique tracing through all stages of metabolism and binding in complete biological systems cannot be so easily effected using fluorescence. Isotopic labeling in a non-labile molecular location remains a more definitive and versatile tool for the biochemist. ${ }^{14} \mathrm{C}$ provides the widest possible use of an isotope label as a substitute for stable carbon atoms in organic molecules.

\section{CAMS biomedical program}

The CAMS biomedical AMS program has three components: the internal research with direct collaborators, the central service that we provide to regional researchers primarily within the University of California system, and a global measurement effort for worldwide collaborators. The local mode is optimal, with rapid turnaround of sample measurements guiding the further development of internal research into the kinetics and binding of common environmental genotoxins. The AMS data is supplemented by ${ }^{32} \mathrm{P}$ postlabeling TLC and HPLC (high performance liquid chromatography) for identification of compounds bound to DNA bases. We obtain detailed biochemical information of bound compounds using computational methods along with structural information from NMR, fluorescence, mass spectrometry, and gel and capillary electrophoresis. We have sought to widen the application of AMS tracing beyond the particular fields of interest within LLNL by supporting innovative uses of AMS tracing in chemistry, pharmacology, nutrition, and physiology within the University of California. This service over a region is possible only if individual researchers understand and apply the numerous precautions needed to avoid contamination in sample definition and preparation in their own labs. The only effective way to promote these precautions is to have the external collaborators work in our laboratory for a month. This mode of a central measurement facility is not optimal, but it is possible and productive. Finally, as 
the primary facility in the world for biomedical tracing of ${ }^{14} \mathrm{C}$ at attomole levels, we have attracted a number of collaborators from North America and Europe. Long distance research collborations are also not as productive as local research, but until other facilities are established, we provide these measurements as resources permit. These collaborations include studies of the possible genotoxic side effects of important pharmaceuticals.

CAMS is used for biomedical ${ }^{14} \mathrm{C}$ measurements only 2 full days and 2 half days per month, but has averaged 450 samples per month in the last half year. We have measured over 200 research samples in times as short as 12 hours. Four hundred samples might be measured in a single day if the graphite samples were prepared by the originating laboratory or a number of preparation sites, as is done in our natural ${ }^{14} \mathrm{C}$ measurement program. This throughput is possible because our system has recently been automated to eliminate the human operator, and we have installed a pneumatically operated sample changer[25] that holds 64 samples. We have yet to fully implement "hot" sample safeguards, and an operator must remain nearby when potentially high ${ }^{14} \mathrm{C}$ concentration samples are measured.

Batch processing of samples in sealed tubes within a muffle furnace[26] successfully produces 150-250 samples every week from the efforts of a single preparation technician. We use graphite condensed on a cobalt catalyst as the sample presentation in a cesium sputter ion source. The low vapor pressure and ease of confinement of potentially "hot" samples argue for using a solid sample phase rather than the potentially more easily processed gas phase. The future of biomedical AMS must rely on a more direct insertion of the sample into the ion source, whether as a modified tissue or as a stream of $\mathrm{CO}_{2}$ from a combustion chamber or gas chromatograph acting as a carbon analyzer. Biomedical samples occasionally differ from the expected isotope content by 5 or 6 orders of magnitude. The high end of these variations have contaminated the graphite-sputtering ion source on several occassions, to the point of requiring dismantling and cleaning. Any ion source/sample combination must have a robustness against memory effects extending over 4-8 orders of magnitude with self-cleaning occuring on the order of minutes. 


\section{Applications in xenobiotic research}

The damage caused by a toxin or the benefit derived from a therapeutic is a function of the dose delivered to an organ, the time the dose remans in the tissue, and the binding mechanism and affinity of the chemical to a biomolecular fraction. Thus, a dose and time response curve for each organ is required for assessing the risk of that organ to damage (or benefit) from a chemical. The need for high throughput of biomedical AMS is seen by multiplying the 10-15 organs or tissues of interest by a minimum of 5 doses in a replicate of 3 animals over 5-10 time points after an acute dose or during a chronic dose. Such an experiment has a minimum of 750 samples. We have performed several total kinetic studies in testing the generally applied assumption of linearity from high experimental doses of tens of milligrams of toxin per kilogram of animal body weight $(\mathrm{mg} / \mathrm{kg})$ to the environmentally relevant doses of a few $\mathrm{ng} / \mathrm{kg}$ to $\mu \mathrm{g} / \mathrm{kg}$.

Figure 1 shows the specific dose as a function of time of ${ }^{14} \mathrm{C}$-labeled 2 -amino-1methyl-6-phenylimidazo[4,5-b]pyridine (PhIP), a potent rodent carcinogen, in a few organs following an administered acute dose equivalent to the amount that a $70 \mathrm{~kg}$ person would ingest from $200 \mathrm{~g}$ of cooked ground beef[20]. The maximum specific organ dose occurs at one half hour or less after exposure, and the organs which metabolize and eliminate the toxin, the liver and kidney, contain the highest concentrations. Within 6 hours, most of the toxin has been removed from the system. The attomole sensitivity of AMS is sufficent for detecting the exposure not only in these primarily affected organs, but also in nearly unaffected tissue such as muscle and in small, but important, organs such as the pancreas. No other analytical technique can trace the initial compound through all organs at this sensitivity with so little chemical purification. The tissues were simply dissected, mg-sized aliquots selected, dried and combusted to $\mathrm{CO}_{2}$ for conversion to graphite and subsequent measurement. The PhIP is labeled in a non-labile position within the primary heterocycle of the molecule. Any excess ${ }^{14} \mathrm{C}$ over that in the control animals is thus attributable to the presence of the functional portion of the initial molecule.

Figure 2 shows the fraction of the daily dose of ${ }^{14} \mathrm{C}$-labeled 2 -amino-3.8dimethylimidazo[4,5-f]quinoxaline (MeIQx), another potent rodent carcinogen found 
in cooked red meats, retained in various tissues after 7 days of chronic feeding over a range of doses from $0.5 \mathrm{mg} / \mathrm{kg}$ to $1 \mathrm{ng} / \mathrm{kg}$. The data represent the average of 3 animals at each dose. The specific dose is plotted as a fraction of administered dose versus the administered dose in order to emphasize any non-linear effects. A linear response to dose would produce a straight line across the dose range. As expected, the organs involved in elimination (liver and kidney) contain the highest levels, and the brain contains the lowest levels over all doses. The efficient metabolism of the compound is seen in the low level of MeIQx circulating in the blood. A linear response to administered dose is seen between the two highest doses, both of which are already well below the doses used in "conventional" experiments. Animal to animal variations are large at the low doses, and only the average point is plotted here. Error bars have been left off for clarity, but are large enough to statistically preclude definitive conciusions of non-linearity for any one organ. However, the consistent deviation from linearity for all organs suggests that a higher fraction of the administered dose remains sequestered in the organs at realistic exposures than at the usual high research doses. In particular, the DNA extracted from the liver and rigorously purified over ion exchange columns indicates a possbly higher retention fraction at lower doses than at high doses.

\section{Biomolecular Interactions}

The primary new development in biomedical AMS is the detailed analysis of the specific binding of chemicals in targeted tissues. Simple dissection and measurement are sufficent to study the kinetics of xenobiotics at very low doses as described above, but the attomole sensitivity of AMS can also be combined with traditional and developing methods of biochemical separation and identification to yield information about the interaction of labeled compounds with specific biomolecules extracted from living systems. Shapiro. et. al [15] describe a method of determining the very slow turnover rate of stable proteins using the worldwide

- natural labeling caused by atmospheric bomb testing in the early 1960's. They quantify the mean residence time of elastin molecules in human lungs from cadavers whose ages at death span 6-78 years, with the 20-40 year old subjects retaining the largest fraction of excess bomb carbon. A fit to the excess ${ }^{14} \mathrm{C}$ in the extracted protein over the ambient ${ }^{14} \mathrm{C}$ levels at the times of death indicate a mean residence of 72 years (40-180 years at $95 \%$ confidence). Hellerstein, et al.[27] 
describe an attempt to measure the mean residence time of myosin in rat and human muscle tissue after subjects received $\mu \mathrm{Ci}$ doses of ${ }^{14} \mathrm{C}$-labeled leucine orally. The sensitivity of AMS allows for the extraction of relatively small biopsies of thigh muscle from the human volunteers. The residence time in humans could not be determined from the data taken, but the rate of incorporation of monomers into human biopolymers was shown to be remarkably less than that in rats. In both of these cases the specific proteins were separated and purified using enzyme digestions and precipitaion from controlled chemical solutions. Dialysis and molecular weight filtering often aid in final cleansing of the precipitate. The identity of the extracted protein is demonstrated by succesive measures of the properties of the extract until stable results are obtained.

More definitive isolation of biomolecules is effected by a number of techniques that rely on transport properties of the molecules through a medium: HPLC (high performance liquid chromatography), TLC (thin layer chromatography), GE (gel electrophoresis), or CE (capillary electrophoresis); or that rely on binding interactions of the molecules: IA (immunoassays) or CC (column chromatography by ion exchange, affinity, etc.).We apply several of these methods to the definition of biomolecules prior to the quantification of the bound, labeled compounds that interacted with them [28]. AMS is a powerful detector for in vivo biochemical research when combined with these techniques, but we cannot overemphasize the need for exceedingly careful laboratory technique to avoid contamination from the initial highly labeled compounds in the final biochemically separated fraction. We have never seen evidence of sample contamination in the proces of converting samples to graphite for measurement, and we have seldom seen contamination in the ion source which did not self-heal in a resaonable time. However, contaminations during biochemical separation occur frequently when strict procedures are not followed. The most effective means of contamination control is to use disposable materials and containers for every sample and every process. Thus, TLC, IA, and CC appear to be the most attractive technologies, but the established techniques of HPLC and GE offer superior molecular definition and are more readily correlated to previous research. Although each gel in $\mathrm{GE}$ is newly cast, there is common equipment used in the electrophoresis that must be carefully cleaned and protected from exposure to very high ${ }^{14} \mathrm{C}$ levels. Despite the need to reuse the injector, columns, and tubing, the quality of HPLC separation makes it a compelling method for 
quantification by AMS.

We quantify the binding of potentially genotoxic compounds to DNA by measuring the amount of the labeled compound that is found bound to the DNA after a rigorous purification process. The DNA is first extracted from and physically and chemically lyzed tissue, such as liver, by centrifuge separation of the nuclear component, enzyme digestion of proteins, and precipitation of the DNA. The DNA is then further purified over ion exchange micro-columns that are commonly sold for the separation of plasmid DNA prior to PCR (polymerase chain reaction) amplification or sequencing operations. These columns are extremely specific to separating small DNA oligomers from protein and other molecular species, are designed for single use, have accepted protocols, and cost only a few dollars per sample. This purified DNA can then be measured directly for specific dose quantification, but can also the be used to detemine the type of chemical reaction of the compound with the DNA. We obtained the liver DNA from a mouse that had been acutely dosed with MeIQx at $20 \mathrm{mg} / \mathrm{kg}$. The DNA was column purified and then hydrolyzed by acids or enzymes. The hydrolyzed DNA was thus reduced to its constituent four bases (adenine, cytosine, guanine, and thymine) or the corresponding nuclentides . A $7 \mu \mathrm{g}$ sample of these bases in solution were injected into an HPLC (Rainin Instruments), using a C-18 reverse phase column at a solvent flow rate of $1 \mathrm{ml} / \mathrm{min}$ on a gradient of $0-10 \% \mathrm{MeOH}$ in $0.01 \mathrm{TEA}$ bufer for 20 minutes followed by a linear increase in $\mathrm{MeOH}$ concentration to a endpoint of $80 \%$ over 20 minutes and held at $80 \%$ for 10 minutes. A UV detector found the nucleotide peaks in the eluent at retention times of $6,11.5,13$ and 16 minutes as shown in Figure 3. No other significant peaks were detected by UV absorption. We used an automatic fraction collector to isolate single minute aliquots of the eluent. These aliquots were partially dried in a vacuum centrifuge (Savant) and then diluted into $100 \mu \mathrm{l}$ of $20 \mathrm{mg} / \mathrm{ml}$ tributyrin in $\mathrm{MeOH}$ as a source of $1.2 \mathrm{mg}$ of low- ${ }^{14} \mathrm{C}$ carrier carbon. The samples were further dried and combusted to $\mathrm{CO}_{2}$ prior to conversion to graphite for AMS measurement. The amount of ${ }^{14} \mathrm{C}$ found in the sample was related to the amount of labeled MeIQx in the eluent fractions using the known specific activity of the initial MeIQx and the measured quantity of ${ }^{14} \mathrm{C}$ in aliquots of the carrier carbon alone. DNA from an undosed control mouse was similarly analyzed, and an HPLC trace having no sample injected was analyzed to determine contamination levels in the HPLC column and injector. The data are shown as an overaly of the UV absorption data in 
Figure 3. The ${ }^{14} \mathrm{C}$ peak corresponding to the fraction retaining the MeIQx is obvious at $35 \mathrm{~min}$. retenticn and quantifies $69 \mathrm{fmol}$ of the compound. The solvent blank run showed a sensitivity above any column contamination of 30-50 amol/min, and the undosed mouse showed a complete experiment background of $2000 \mathrm{amol} / \mathrm{min}$ at 35 minutes retention and $50 \mathrm{amol} / \mathrm{min}$ at other retention times. The high level at 35 $\min$ is from contaminating MeIQx retained in the injector. The dosed mouse DNA contained an average of $9.3 \pm 1.4 \mathrm{fmol} \mathrm{MeIQx} / \mu \mathrm{g} \mathrm{DNA}$, as determined from $5 \mathrm{HPLC}$ separations.

The power of HPLC-AMS in biochemical research is demonstrated by the interpretation of the singie peak at 35 minutes. MeIQx is expected to bind to the C-8 carbon of guanine. This is shown by the in vitro interaciion of MeIQx with purified guanine[29]. The resultant compounds have a retention time under the above HPLC conditions of 42 and 46 minutes. Injection of simple MeIQx into the HPLC results in a peak at 35 minutes, corresponding to the peak we find from the dosed mouse liver DNA. After careful determination that our purification scheme removes all unbound MeIQx from the DNA, we conclude that the compound may not primarily bind to DNA in vivo through a guanine C-8 adduct or that the adduct is unstable, and may instead bind to the DNA as an intercalation between bases or through conformation binding along one of the grooves. Such binding requires lengthy oligomers and cannot be replicated using single bases in vitro. While MeIQx may indeed covalently bind to guanine, HPLC-AMS suggests that that is not the primary binding mode in vivo.

${ }^{3} \mathrm{H}$ tracing by AMS is under development to complement this identification of biochemical processes by ${ }^{14} \mathrm{C}[14]$. A double-isotope capability for the primary 2 components of organic compounds will permit more complex tracing than the simple identification of bound components after chemical identification. Changes brought about by metabolism prior to binding could be quantified by judicious locations of ${ }^{3} \mathrm{H}$ and ${ }^{14} \mathrm{C}$ isotopes in a single molecule. Alternatively, the interactions of two compounds that may bind synergistically could be measured by labeling the two compounds with the different labels.

\section{Human Subjects in AMS}


Human subjects are being used in experiments tracing long lived isotopes of aluminum and calcium, as mentioned above. The chemical and radiation doses from compounds that are to be traced by AMS are so low that even ${ }^{14} \mathrm{C}$ can be effectively used in living human subjects as in the protein study above. Collaborators at UCSF study the absorption of organic compounds through human epidermal layers to support regulations dealing with the permissible levels of industrial solvents in the work place[30]. Heretofore, they have used Fourier-Transform Infrared spectroscopy (FTIR) to quantify the reflected infrared from the stratum corneum (the outer layer of skin that contains dead cells in a lipid matrix) as an infrared-absorbing compound diffuses into the protective skin layers. Since the infrared does not penetrate farther than a few microns into the skin, successive cell layers are removed by applying tape that adheres to a single layer of cells, removing them along with the tape. For best resolution, a strongly interacting moiety, such as a cyano group, must be part of the traced compound. AMS allows the extension of this study to any ${ }^{14} \mathrm{C}$-labeled compound by using the tape-adhered cell layer as the measured sample. The tape itself contains petroleum carbon, and acts as the carbon carrier for the few fmol of absorbed compound. A hole punch assures that a uniformsized area of the tape is sampled each time. Figure 4 shows the amount of ${ }^{14} \mathrm{C}$ nitrophenol as a function of tape strip number, or, alternatively, the single cell layer, from the arm of a human subject after a $10 \mathrm{nCi} / \mathrm{ml}(200 \mathrm{pmol} / \mathrm{ml}$ or $3.6 \mathrm{ppb})$ aqueous solution of nitrophenol had been applied. The error bars of the AMS measurement are plotted (and not discernable), but the replicate measurements of different parts of the sixth and fifteenth tape strips show the precision of the method. Outliers at tapes 8 and 16 represent either contamination in sampling or an extreme variability across the cells removed at these layers. The outer layer was measured at 60 Modern and the tape is less than 0.1 Modern, so that the data from the deepest layers are well above the sensitivity of AMS. The precision of the AMS technique is greater, more layers are easily measured, and the compound can be followed to greater depths in the epidermis than the with the FTIR method. The slope of the curve can be related to the penetrant concentration in the stratum corneum.

Often a compound needs to be traced that cannot be labeled or was not labeled when it entered the subject. For example, complex drugs like taxol or industrial pollutants are not labeled at their source. Thus, a method of bringing the sensitivity of AMS to 
a post-labeling scheme is needed. We have developed a competitive Isotope-Labeled ImmunoAssay (ILIA) that detects unlabeled compounds without the need to inject labeled compounds in the subject. A quantity of antibodies to the specific compound under investigation are bound to a substrate in a concentration well below the expected concentration of the compound. An aliquot of the solution containing the unlabeled compound is added, perhaps after some slight purification from a biological sample. A known quantiity of the same, but ${ }^{14} \mathrm{C}$-labeled, compound is added. The labeled and unlabeled quantities of the compound compete for the limited number of binding sites on the antibodies. After a time for equilibrium, the unbound compounds are separated from the substrate-held antibodies, which are washed and diluted in a solution of carbon carrier before combustion and conversion to graphite. The ${ }^{14} \mathrm{C}$ removed with the antibodies will be inversely proportional to the amount of the original, unlabeled compound in the solution. Figure 5 plots a measure of the ${ }^{14} \mathrm{C}$ content, expressed as fraction of labeled compound inhibited from binding, versus the known quantity of unlabeled azidothymidine (AZT, a reverse transcriptase inhibitor) added. The total reaction volume was $60 \mu \mathrm{l}$, and $20 \mathrm{fmol}$ of antibody and labeled AZT were used in the competition. Figure 5 is a standard curve for measuring unknown amounts of the compound through comparison with the inhibition curve of these known amounts. In most immunoassays, there are separate standard curves for every decade or so in concentration. Because AMS measures low levels of ${ }^{14} \mathrm{C}$ as precisely as higher levels, this standard curve extends over 4 decades, greatly decreasing the number of assays that must be performed to determine the unknown concentrations in a widely varying set of solutions. Since antibodies can be produced for almost any chemical compound or protein. ILIA could be used in tracing or quantifying specific compounds, such as therapeutics, in humans. We also plan to develope tests for DNA adducts and other biomolecular combinations using this method.

\section{Conclusion}

The experience in biomedical AMS over the past 3 years shows that AMS provides excellent sensitivity and precision in a number of important applications ranging from quantifying bone resorption to testing for genotoxicity and determining the 
risks of dermal exposure to organics. Since there is still only one laboratory that devotes a large part of their AMS program to biomedical research, we cannot yet extrapolate the field much beyond the next year or so. There are toxicological institutes presently investigating the purchase of AMS facilities that have learned about AMS through collaborations with CAMS at Lawrence Livermore. While we are trying to demonstrate the use of AMS in pharmacology and other fields, we cannot work in-house, the most efficient way, in areas in which we have little or no expertise. Other institutions could well carve out biomedical niches for effective demonstration and funding purposes. We are turning down more collaborations as our time and efforts become better defined and used. These prospective collaborators have not found other laboratories willing to work with them in developing extensive research programs.

Once a critical mass of demonstration research has been done at established AMS laboratories, facilities dedicated to biomedical research can be expected to arise. Although small machines of limited application are being proposed for use in these facilities[31], the use of AMS and the types of possible experiments have not yet been constrained enough to show that full AMS capabilities over a number of isotopes are not needed for a vigorous specialized facility. We are intending to build a dedicated facility within the next few years, and it should contain a spectrometer based on a machine capable of holding at least $3 \mathrm{MV}$. With the developing detection of filtered isotopes using satellite $\mathrm{x}$-rays[32], such a machine will provide guaranteed ${ }^{14} \mathrm{C}$ and ${ }^{3} \mathrm{H}$ detection at the highest sensitivities and will have promise of detecting a fair number of other medically interesting isotopes.

The most important improvements to look for in the next few years will be in sample presentation and ionization and in expansion in the breadth of biomedical applications. We can presently acheive sufficiently low sample cross talk only by using low-vapor-pressure graphite to cover a $10^{5}$ range from up from $1 \mathrm{amol}{ }^{14} \mathrm{C} / \mathrm{mg}$ C. We look forward to the demonstration in the next few years of ion sources that can use gas feed over these same ranges. We have demonstrated the value of the wide dynamic range and sensitivity of AMS to a still-limited spectrum of primarily toxicologists, pharmacologists and nutritionists. Expansion of this base of biomedical users requires more access to more AMS facilities over a wide range of interesting isotopes. 
Work was performed under the auspices of U.S. D.O.E. at Lawrence Livermore National Laboratory under contract W-7405-ENG-48.

\section{References}

1. O. Meirav, R.A. Sutton, D. Fink, R. Middleton, J. Klein, V.R. Walker, A. Halabe, D. Vetterli and R.R. Johnson, Nucl. Inst. and Meth. B52 (1990) 536.

2. J. Barker, J.P. Day, T.W. Aitken, T.R. Charlesworth, R.C. Cunningham, P.V. Drumm, J.S. Lilley, G.W.A. Newton and M.J. Smithson, Nucl. Inst. and Meth. B52 (1990) 540.

3. D. Elmore, M.H. Bhattacharyya, N. Sacco-Gibson and D.P. Peterson, Nucl. Inst. and Meth. B52 (1990) 531.

4. T. Straume, R.C. Finkel, D. Eddy, P.W. Kubik, H.E. Gove, P. Sharma, S. Fujita and M. Hoshi, Nucl. Inst. and Meth. B52 (1990) 552.

5.S.P.H.T. Freeman, C.R. Bronk and R.E.M. Hedges, Nucl. Inst. and Meth. B52 (1990) 405.

6. J.S. Felton, K.W. Turteltaub, J.S. Vogel, R. Balhorn, B.L. Gledhill, J.R. Southon, M.W. Caffee, R.C. Finkel, D.E. Nelson, I.D. Proctor and J.C. Davis, Nucl. Inst. and Meth. B52 (1990) 517.

7. J.S. Vogel, K.W. Turteltaub, J.S. Felton, B.L. Gledhill, D.E. Nelson, J.R. Southon, I.D. Proctor and J.C. Davis, Nucl. Inst. and Meth. B52 (1990) 524.

8. J.A. Edwardson, P.B. Moore P, I.N. Ferrier, J.S. Lilley, G.W. Newton, J. Barker. J. Templar, J.P. Day , Lancet 342 (1993) 211.

9. J.P. Day, J. Barker, L.J. Evans, J. Perks, P.J. Seabright, P. Ackrill, J.S. Lilley, P.V. Drumm and G.W. Newton, Lancet 337 (1991) 1345.

10. O. Meirav, R.A. Sutton, D. Fink, R. Middleton, J. Klein, V.R. Walker, A. Halabe, D. Vetterli and R.R. Johnson, American Journal of Physiology 260 (1991) F466.

11. J.R. Southon, G.J. Kost and M.S. Bishop, these proceedings. 
12. K. Kato, M. Habara, Y. Yoshizawa, U. Biebel, G. Haberstock, J. Heinzl, G. Korschinek, H. Morinaga, E. Nolte, International Journal of Radiation Biology 58 (1990) 661.

13. T. Straume, S.D. Egbert, W.A. Woolson, R.C. Finkel, Health Physics 63 (1992) 421.

14. M.R. Roberts, C. Velsko and K.W. Turteltaub, these proceedings

15. S.D. Shapiro, S.K. Endicott, M.A. Province, J.A. Pierce, E.J. Campbell, Journal of Clinical Investigation 87 (1991) 1828.

16. M.L. Williams, J.S. Vogel, R. Ghadially, B.E. Brown and P.M. Elias, Archives of Dermatology 128 (1992) 1065.

17. K.W. Turteltaub, J.S. Felton, B.L. Gledhill, J.S. Vogel, J.R. Southon, M.W. Caffee, R.C. Finkel, D.E. Nelson, I.D. Proctor and J.C. Davis, Proceedings of the National Academy of Sciences of the United States of America 87 (1990) 5288.

18. J.S. Felton, K.W. Turteltaub, B.L. Gledhill, J.S. Vogel, M.H. Buonarati and J.C. Davis, Progress in Clinical and Biological Research 372 (1991) 243

19. J.S. Felton, M.G. Knize, M. Roper, E. Fultz, N.H. Shen, and K.W. Turteltaub, Cancer Research 52 (1992) 2103s

20. K.W. Turteltaub, J.S. Vogel, C.E. Frantz and N.H. Shen, Cancer Research 52 (1992) 4682.

21. S. Kato, S. Petruzzelli, E.D. Bowman, K.W. Turteltaub, B. Blomeke, A. Weston and P.G. Shields, Carcinogenesis 14 (1993) 545.

22. K.W. Turteltaub, J.S. Vogel, C.E. Frantz, M.H. Buonarati and J.S. Felton . Environmental Health Perspectives 99 (1993) 183.

23. S.P.H.T. Freeman, Nucl. Inst. and Meth. B79 (1993) 627.

24. A. Long, R.S. Kra, F. Moskovitz and E.M. Scott, eds. Proceedings of the Int. Workshop on Intercomparison of Radioisotope Laboratories, Radiocarbon 32/3 (1990).

25. M.R. Roberts, P.J. Norman, J. Garibaldi and R. Hornady, these proceedings. 26. J.S. Vogel, Radiocarbon, 34 (1992) 344-350. 
27. M. Hellerstein, Abstract, Am. Soc. Mass Spec. Meeting, May 31-June 5, 1993.

28. M.R. Creek, C.E Frantz, E. Fultz, K. Redwine, N. Shen, K. Turteltaub and J.S. Vogel These proceedings.

29. R.J. Turesky, S.C. Rossi, D.H. Welti, J.O. Lay and F.F. Kadlubar, Chem. Res. in Tox. 5 (1992) 479.

30. D. Bommannan, R.O. Potts and R.H. Guy, Journ. Investig. Dermat., 95 (1990) 403.

31. K. Purser, these proceedings

32. H. Artigalas, M.F. Barthe, J. Gomez, J.L. Debrun, L. Kilius, X.L. Zhao, A.E. Litherland, J.L. Pinault, Ch. Fouillac, P. Caravatti, G. Kruppa and C. Maggiore, Nucl. Inst. and Meth. B79 (1993) 617. 


\section{Figures}

Figure 1. Specific tissue dose as a function of time in mice after an acute interperitoneal injection of $41 \mathrm{ng} / \mathrm{kg}$ of ${ }^{14} \mathrm{C}$ - $\mathrm{PhIP}$ shows an elimination time much shorter than that found with much higher does. Each data point represents the average of 3 animals, and the error bars, where given, are the standard deviation among replicates. AMS is sensitive enough to trace labeled chemicals in small organs as well as the larger ones.

Figure 2. Chronic feeding of rats with a range of doses of ${ }^{14} \mathrm{C}-\mathrm{MeIQx}$ for one week reveals possibly non-linear effects at low doses. The fraction of the daily administered dose found in the organs of 3 replicate rats at each dose is plotted as a function of the administered dose. A linear dose response would yield horizontal lines. The standard deviations among the replicate rats are not shown for clarity, but are large at low doses. While no one organ shows non-linear effects beyond errors, the trends in all organs suggest greater retention at low doses.

Figure 3. The UV absorbance trace of an HPLC after injection of enzyme hydrolyzed DNA from the liver of a mouse exposed to $20 \mathrm{mg} / \mathrm{kg}$ of ${ }^{14} \mathrm{C}-\mathrm{MeIQx}$ shows the four peaks due to the separate nucleotides. No peak from a nucleotide-MeIQx adduct is detected. The ${ }^{14} \mathrm{C}$ trace measured with AMS is superposed. Free ${ }^{14} \mathrm{C}-\mathrm{MeIQx}$ is detected at 35 minute elution. Five repeats quantified the MeIQx a. $9.3 \mathrm{fmol} \mathrm{MeIQx}$ per $\mu \mathrm{g}$ DNA.

Figure 4. The absorption of ${ }^{14} \mathrm{C}$-nitrophenol into the upper layers of human epidermis is shown as a function of individual cell layers. The layers are removed in succession using stips of tape that adhere to the tape upon removal. Uniform spots of the tape and cells are combustedand measured by AMS.

Figure 5. The iogit ( $\mathrm{x} /(1-\mathrm{x})$ ) of inhibition in binding ${ }^{14} \mathrm{C}$-AZT on $20 \mathrm{fmol}$ of AZTspecific antibody is shown as a function of added unlabeled AZT. Labeled AZT was present in 2 experiments at $20 \mathrm{fmol}$, and in one at $2 \mathrm{fmol}$. AMS-based immunoassays show a very wide dynamic range due to AMS sensitivity at low concentrations. 


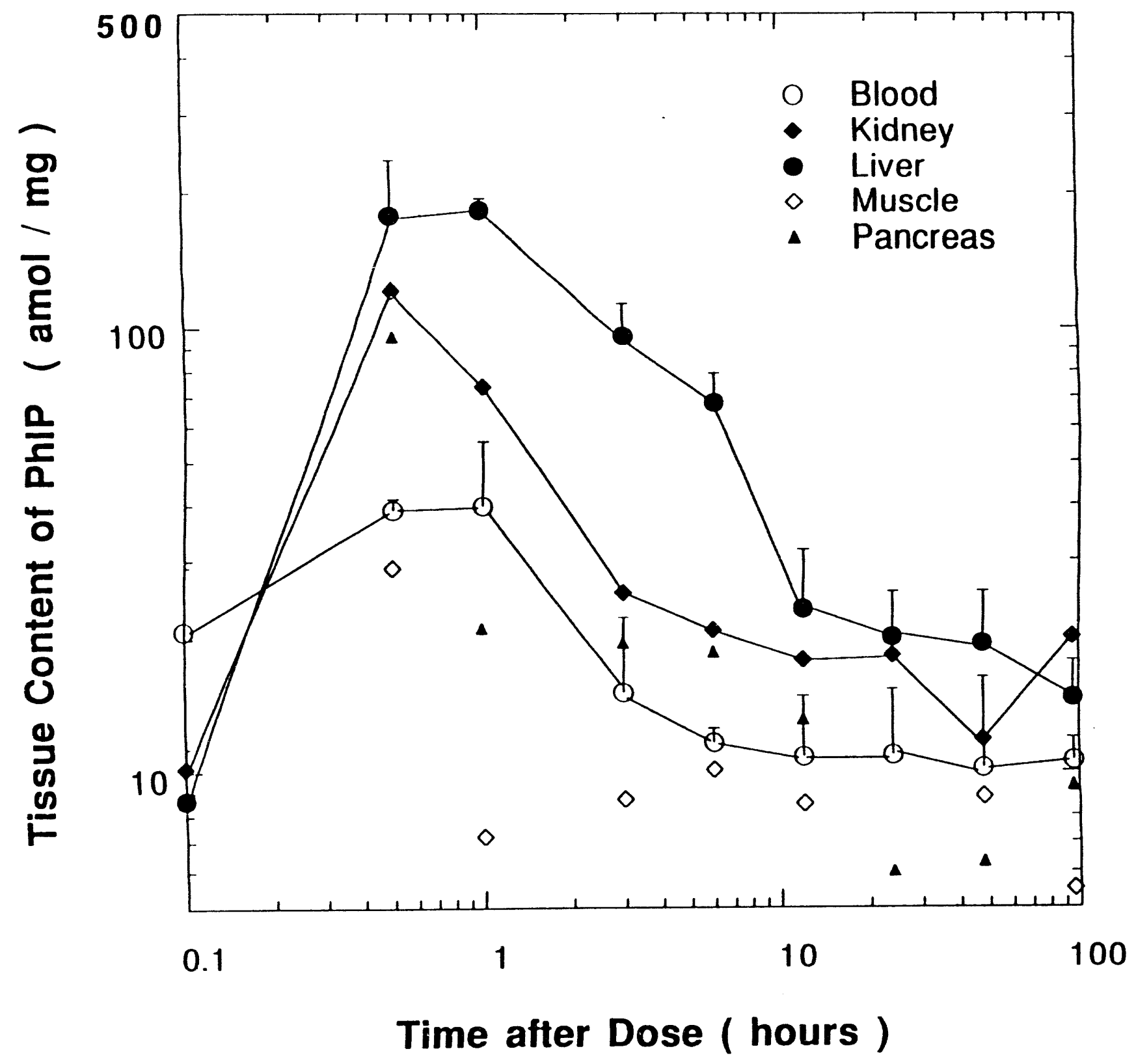




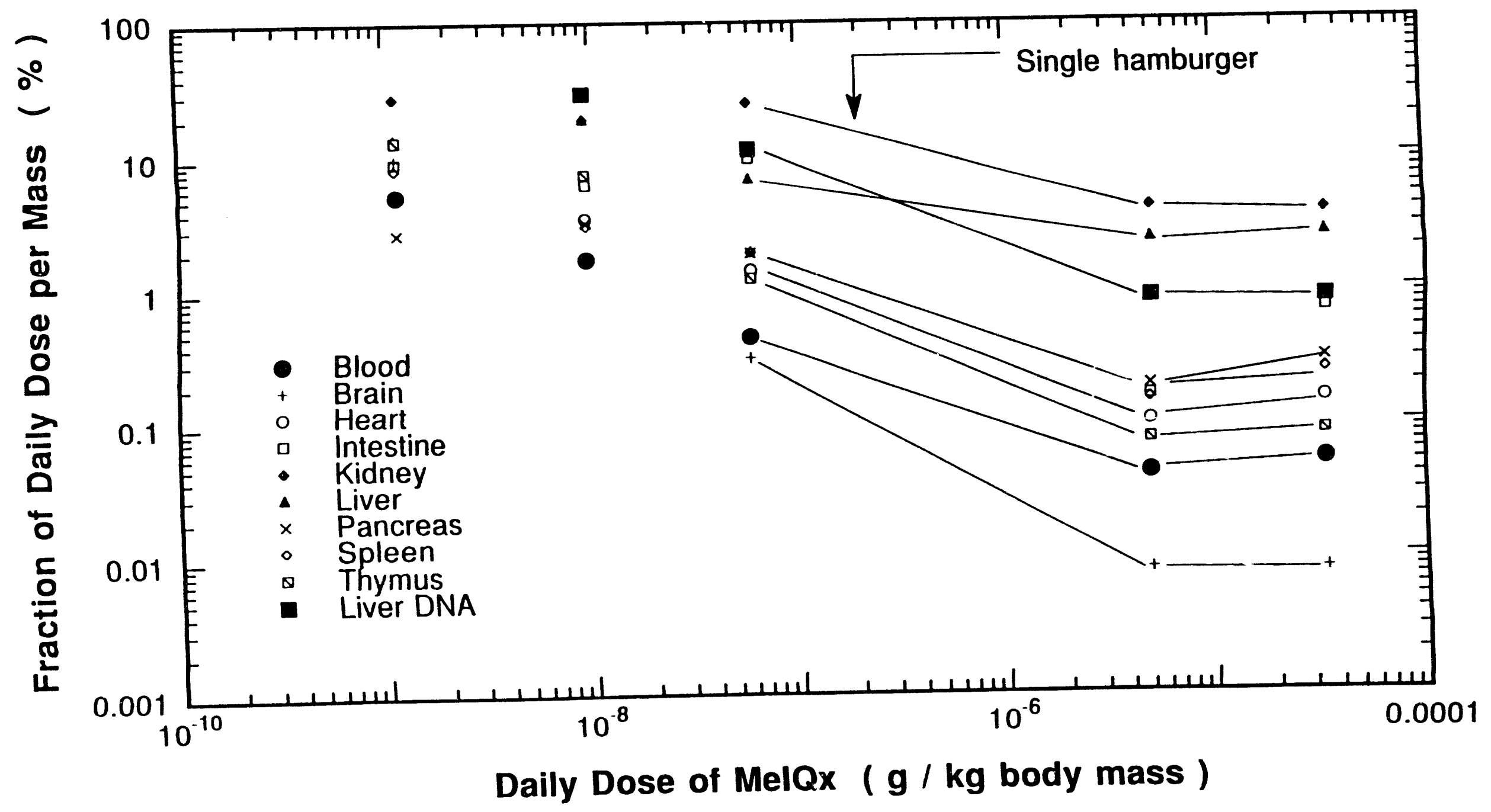




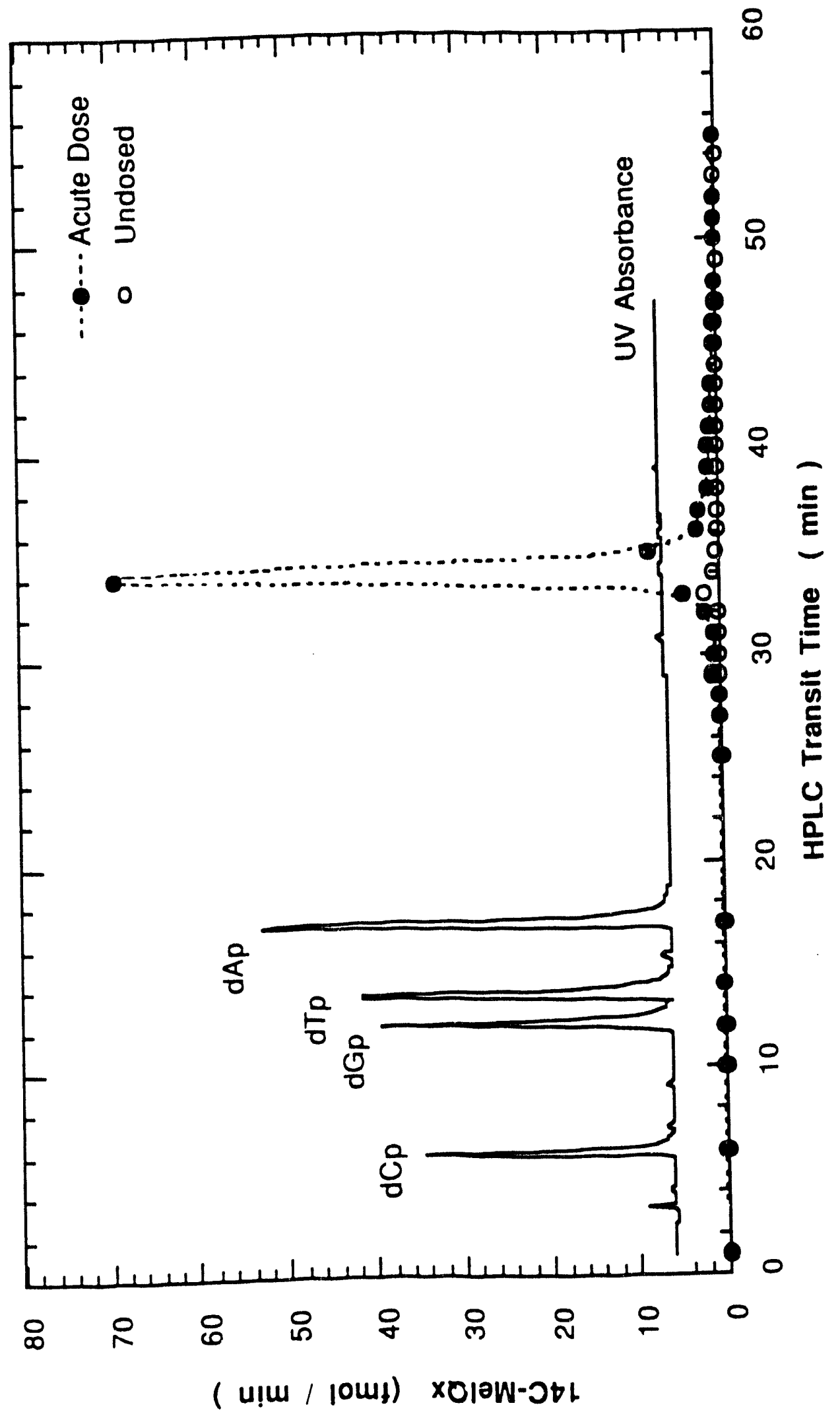




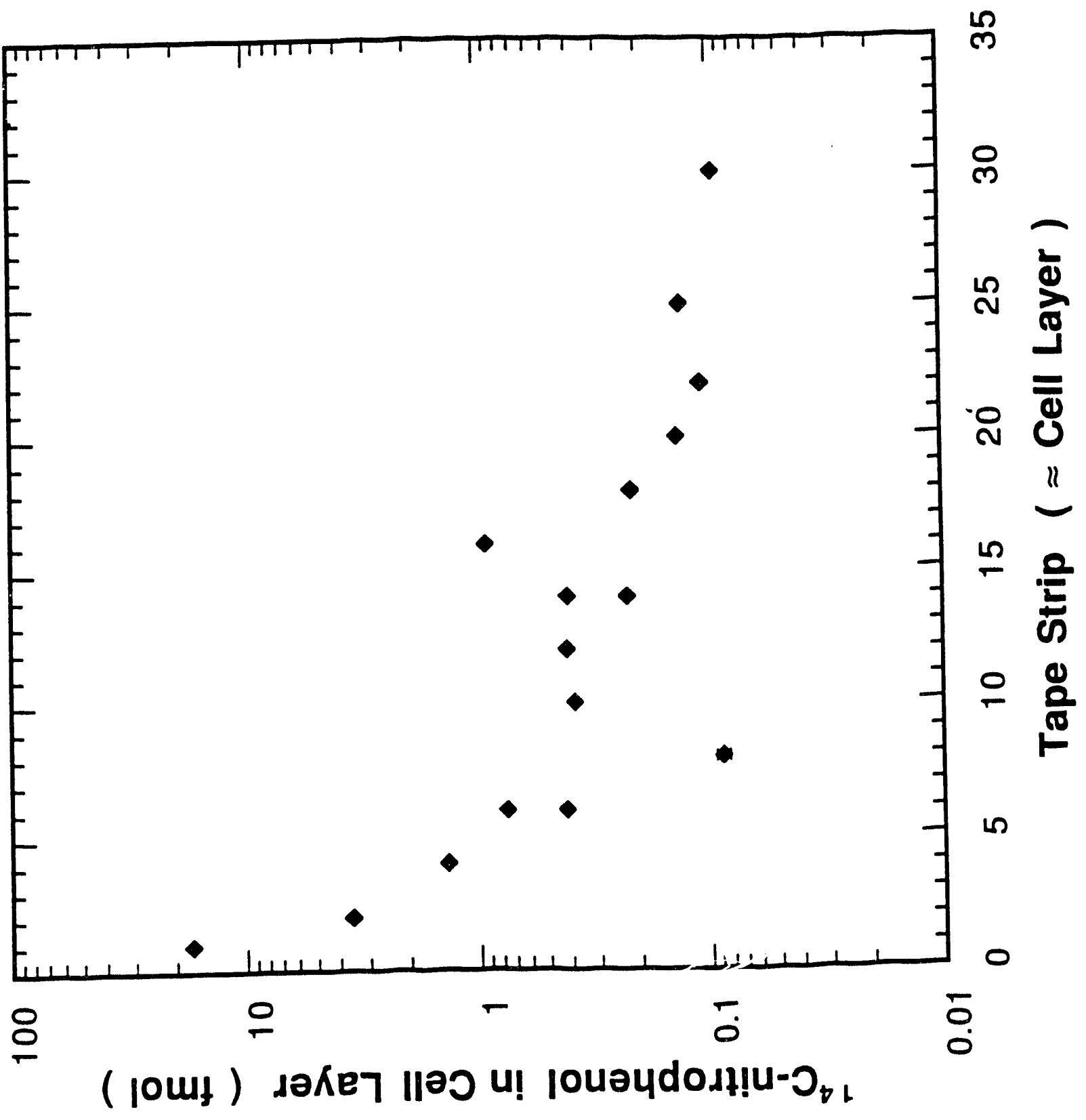




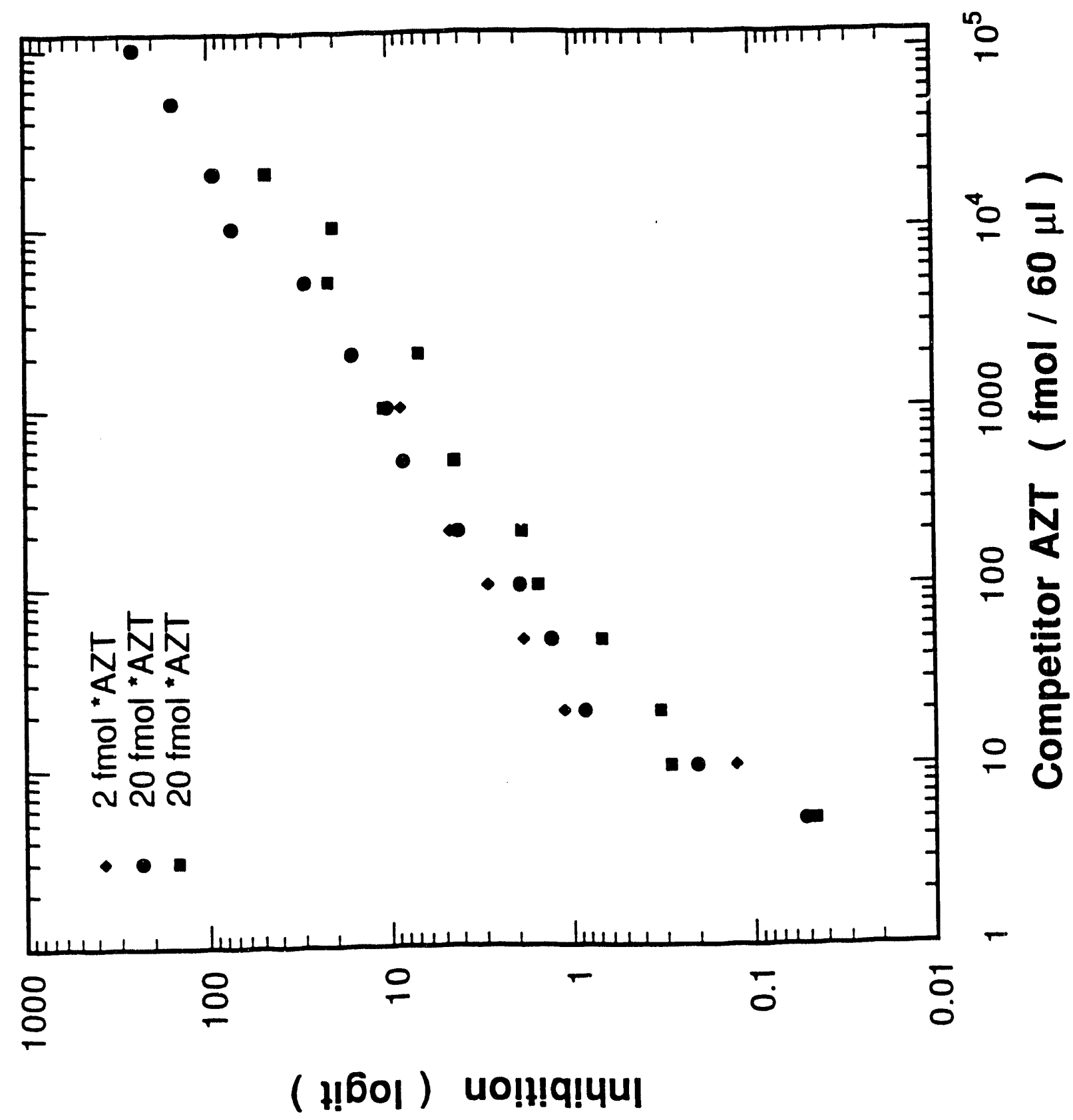



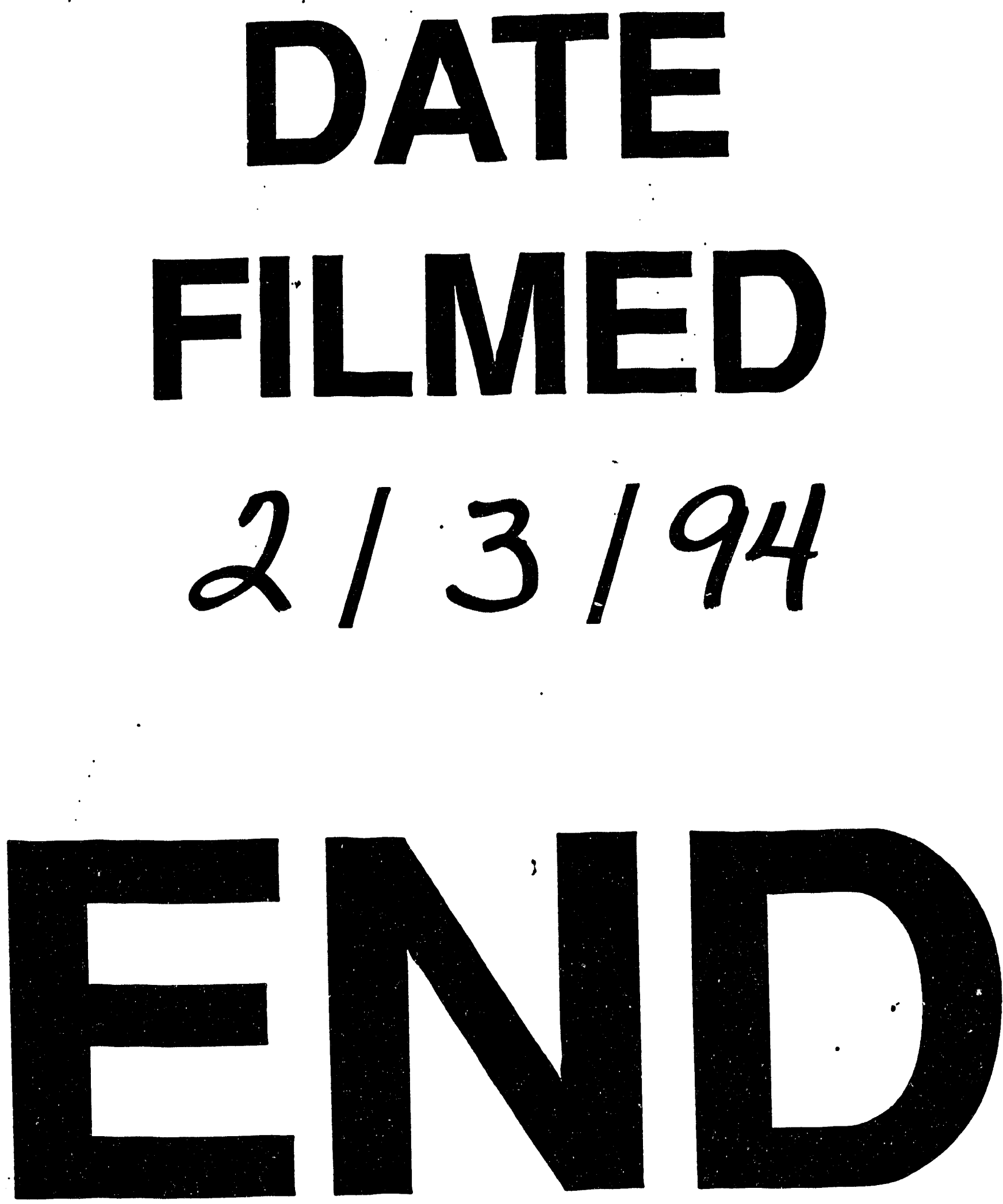